\title{
Correction
}

\section{Correction: Prevalence of Diabetes in the Republic of Ireland: Results from the National Health Survey (SLAN) 2007}

\section{The PLOS ONE Staff}

There is an error in the second sentence of the "Results" subheading under the "Abstract" section. The correct sentence for this section is:

"Amongst adults aged 45+ years, the prevalence of doctordiagnosed diabetes was $6.1 \%(95 \%$ CI $5.3 \%-6.9 \%)$ and undiagnosed diabetes was 2.8\% (95\% CI 1.4\% - 4.1\%)."

\section{Reference}

1. Balanda KP, Buckley CM, Barron SJ, Fahy LE, Madden JM, et al. (2013) Prevalence of Diabetes in the Republic of Ireland: Results from the National Health Survey (SLAN) 2007. PLoS ONE 8(10): e78406. doi:10.1371/journal.pone.0078406
Citation: The PLOS ONE Staff (2014) Correction: Prevalence of Diabetes in the Republic of Ireland: Results from the National Health Survey (SLAN) 2007. PLoS ONE 9(6): e99471. doi:10.1371/journal.pone.0099471

Published June 3, 2014

Copyright: (c) 2014 The PLOS ONE Staff. This is an open-access article distributed under the terms of the Creative Commons Attribution License, which permits unrestricted use, distribution, and reproduction in any medium, provided the original author and source are credited. 